\section{(6) OPEN ACCESS}

\begin{abstract}
${ }^{1}$ Centre for Neuroendocrinology, Royal Free Campus, University College Medical School, London, UK

${ }^{2}$ Department of Nephrology, Whittington Health, London, UK

${ }^{3}$ Department of Endocrinology, Hammersmith Hospital, London, UK

${ }^{4}$ Department of Diabetes and Endocrinology, Whittington Health, London, UK ${ }^{5}$ Department of Clinical Biochemistry, Royal Free Hospital, London, UK ${ }^{6}$ Department of Clinical Biochemistry, Whittington Health, London, UK

${ }^{7}$ Department of Endocrinology, Northwick Park Hospital, London, UK
\end{abstract}

\section{Correspondence to} Dr PloutarchosTzoulis, Centre for Neuroendocrinology, Royal Free Campus, University College Medical School, London NW3 2QG, UK; Ploutarchos.tzoulis@nhs.net

Received 3 July 2014 Revised 1 October 2014 Accepted 29 October 2014 Published Online First 14 November 2014

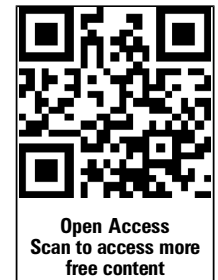

CrossMark

To cite: Tzoulis $P$, Evans $R$ Falinska $A$, et al. Postgrad Med J 2014;90:694-698.

\title{
Multicentre study of investigation and management of inpatient hyponatraemia in the UK
}

\author{
Ploutarchos Tzoulis, ${ }_{1}^{1}$ Rhys Evans, ${ }^{2}$ Agnieszka Falinska, ${ }^{3}$ Maria Barnard, ${ }^{4}$ Tricia Tan, ${ }^{3}$ \\ Emma Woolman, ${ }^{5}$ Rebecca Leyland ${ }^{5}$ Nick Martin, ${ }^{5}$ Rebecca Edwards, ${ }^{6}$ \\ Rebecca Scott, ${ }^{7}$ Kalyan Gurazada, ${ }^{1}$ Marie Parsons, ${ }^{6}$ Devaki Nair, ${ }^{5}$ Bernard Khoo, ${ }^{1}$ \\ Pierre Marc Bouloux ${ }^{1}$
}

\begin{abstract}
Purpose Hyponatraemia is associated with significant morbidity and mortality. The objectives of this study were to evaluate the investigation and management of hyponatraemia and to assess the use of different therapeutic modalities and their effectiveness in routine practice.
\end{abstract}

Study design This multicentre, retrospective, observational study was conducted at three acute NHS Trusts in March 2013. A retrospective chart review was performed on the first 100 inpatients with serum sodium $(\mathrm{sNa}) \leq 128 \mathrm{mmol} / \mathrm{L}$ during hospitalisation.

Results One hundred patients (47 male, 53 female) with a mean \pm SD age of $71.3 \pm 15.4$ years and nadir $\mathrm{sNa}$ of $123.4 \pm 4.3 \mathrm{mmol} / \mathrm{L}$ were included. Only $23 / 100(23 \%)$ had measurements of paired serum and urine osmolality and sodium, while $31 \%$ had an assessment of adrenal reserve. The aetiology of hyponatraemia was unrecorded in $58 \%$ of cases. The mean length of hospital stay was 17.5 days with an inpatient mortality rate of $16 \%$. At hospital discharge, 53/84 (63.1\%) patients had persistent hyponatraemia, including 20/84 (23.8\%) with sNa $<130 \mathrm{mmol} / \mathrm{L}$. Overall $37 / 100$ (37\%) patients did not have any treatment for hyponatraemia. Among 76 therapeutic episodes, the most commonly used treatment modalities were isotonic saline in $38 / 76$ cases (50\%) and fluid restriction in $16 / 76(21.1 \%)$. Fluid restriction failed to increase $\mathrm{sNa}$ by $>1 \mathrm{mmol} / / /$ day in

$8 / 10(80 \%)$ cases compared with 4/26 (15.4\%) for isotonic saline.

Conclusions Underinvestigation and undertreatment of hyponatraemia is a common occurrence in UK clinical practice. Therefore, development of UK guidelines and introduction of electronic alerts for hyponatraemia should be considered to improve clinical practice.

\section{INTRODUCTION}

Hyponatraemia, defined as serum sodium $(\mathrm{sNa})$ concentration below $135 \mathrm{mmol} / \mathrm{L}$, is the most common electrolyte abnormality encountered in hospitalised patients, with a reported incidence of $30-42 \% .{ }^{12}$ Hyponatraemia is an independent risk factor for mortality ${ }^{4}$ and is associated with an increase in length of hospital stay ${ }^{5}$ and hospital resource utilisation. ${ }^{6}$

Accurate diagnosis of hyponatraemia is necessary to guide effective treatment. However, numerous single-centre studies in the UK have consistently reported underutilisation of appropriate biochemical tests in the investigation of hyponatraemia. ${ }^{7-13}$ It is unclear to what extent inadequate investigation of hyponatraemia reflects UK clinical practice in general. There is also a paucity of data about the utilisation of different therapeutic modalities for hyponatraemia and their efficacy in a real world setting.

This study describes current clinical practice in three acute UK hospitals. The objectives were to evaluate the investigation and management of inpatient hyponatraemia and to assess the use of different therapeutic modalities and their effectiveness.

\section{METHODS}

\section{Study design}

This was a multicentre, retrospective, observational study examining the investigation and management of 100 consecutive inpatients with serum sodium $(\mathrm{sNa}) \leq 128 \mathrm{mmol} / \mathrm{L}$.

Recruitment started on 1 March 2013 and ended on 28 March 2013 when a total of 100 patients were reached. It was conducted simultaneously at three acute NHS Trusts in London: centre 1, an 850 -bed teaching hospital; centre 2 , including 850 beds across two teaching hospitals; and centre 3 , a 450-bed district general hospital. None of the three institutions had local guidelines for the management of hyponatraemia.

\section{Patient selection}

We defined inpatient hyponatraemia as an $\mathrm{sNa}$ concentration $\leq 128 \mathrm{mmol} / \mathrm{L}$ at any point during hospital admission. Patients were identified through an automated laboratory database search. A cut-off of $128 \mathrm{mmol} / \mathrm{L}$ was selected because previous data from this hospital cohort showed an upward inflection in inpatient mortality below that threshold. ${ }^{3}$ Subjects with hyperglycaemia were included only if their corrected sNa was $\leq 128 \mathrm{mmol} / \mathrm{L}$. If venous glucose was $15-24.4 \mathrm{mmol} / \mathrm{L}$, sNa was corrected by $1.6 \mathrm{mmol} / \mathrm{L}$ for every $5.6 \mathrm{mmol} / \mathrm{L}$ increase in glucose concentration above $7 \mathrm{mmol} / \mathrm{L}$; if glucose was $>24.4 \mathrm{mmol} / \mathrm{L}$, a correction factor of $2.4 \mathrm{mmol} / \mathrm{L}$ was used. ${ }^{14}$

\section{Data collection}

Hospital case notes, laboratory results, drug prescription charts and discharge letters were retrospectively reviewed for each patient after hospital discharge. Data were collected on age, gender, speciality responsible for each patient, drug history, admission to the intensive care unit, length of hospital stay, outcome of admission, investigations and documented cause of hyponatraemia, $\mathrm{sNa}$ levels at various time points, use of therapeutic modalities, $\mathrm{sNa} 24$ and $72 \mathrm{~h}$ after initiation of treatment, and $\mathrm{sNa}$ at hospital discharge. 
Adequate investigation of hyponatraemia should include clinical assessment of volume status, measurement of paired serum and urine osmolality and $\mathrm{Na}$, thyroid function tests and serum cortisol measurement. The effectiveness of treatment of hyponatraemia was assessed by $\mathrm{sNa}$ concentration at hospital discharge. For the purpose of evaluating the effectiveness of different treatment modalities, 'clear failure' of treatment was defined as a total $\mathrm{sNa}$ increase of $\leq 3 \mathrm{mmol} / \mathrm{L}$ after the $72 \mathrm{~h}$ period after initiation of therapy. Over-rapid correction of hyponatraemia, known to risk osmotic demyelination syndrome, ${ }^{15} 16$ was defined as an sNa increase of $>12 \mathrm{mmol} / \mathrm{L}$ in $24 \mathrm{~h}$.

\section{Data analysis}

All data were recorded on an Access database and then transferred into an Excel spreadsheet. Data were analysed separately for each hospital and for all three hospitals together. Data were summarised using descriptive statistics, with continuous variables being expressed as mean $\pm \mathrm{SD}$, and categorical variables as percentages.

Adequacy of investigation was assessed by the percentage of patients who underwent each of the recommended tests. The proportion of patients with normonatraemia and different degrees of hyponatraemia (mild/moderate/severe) was used to determine the effectiveness of management of hyponatraemia. The percentage of patients who had 'clear failure' and 'over-rapid correction' determined the effectiveness of each therapeutic modality.

\section{RESULTS}

\section{Demographic characteristics}

Across three hospitals in London, 100 patients (47 male, 53 female) were included with a mean \pm SD age of $71.3 \pm 15.4$ years. Centre 1 included 38 patients ( 19 male, 19 female with a mean age of $73.6 \pm 15.1$ years), centre 2 contributed 30 patients (13 male, 17 female aged $68.5 \pm 15.5$ years) and centre 3 contributed 32 patients (15 male, 17 female with a mean age of $70.4 \pm 15.4$ years).

The mean sNa on admission was $128.1 \pm 7.1 \mathrm{mmol} / \mathrm{L}$, and the lowest $\mathrm{sNa}$ during hospitalisation was $123.4 \pm 4.3 \mathrm{mmol} / \mathrm{L}$. In terms of the time point of onset of hyponatraemia, 58/100 $(58 \%)$ patients presented on admission with $\mathrm{sNa} \leq 128 \mathrm{mmol} / \mathrm{L}$ in comparison with $42 / 100(42 \%)$ who developed $\mathrm{sNa}$ $\leq 128 \mathrm{mmol} / \mathrm{L}$ during hospitalisation.

\section{Speciality distribution}

There was a wide distribution of patients within different specialities: $81 / 100(81 \%)$ patients were under the care of medical specialities including geriatrics (18\%), general medicine (11\%), respiratory (9\%), gastroenterology $(9 \%)$, oncology $(6 \%)$, hepatology $(6 \%)$, cardiology (5\%), infectious diseases (5\%), endocrinology (4\%), nephrology (3\%), neurology (3\%) and rheumatology $(2 \%) ; 19 / 100(19 \%)$ patients were under the care of surgical specialities including general surgery (5\%), urology (5\%), orthopaedics $(4 \%)$, cardiothoracic surgery (3\%) and gynaecology (2\%).

\section{Drug history}

Of the 100 patients, 35 were taking ACE inhibitors, 23 loop diuretics, 22 thiazide diuretics, 15 selective serotonin reuptake inhibitors (SSRIs), 14 potassium-sparing diuretics, 12 angiotensin-II receptor antagonists, and 6 tricyclic antidepressants.

\section{Outcome of admission}

The inpatient mortality rate in our cohort was $16 \%$. The mean length of hospital stay was $17.5 \pm 14.8$ days with $9 / 100(9 \%)$ of patients requiring admission to the intensive care unit.

\section{Diagnostic work-up}

Clinical assessment of volume status was documented in 62/100 $(62 \%)$ cases, while paired serum and urine osmolality and $\mathrm{Na}$ were measured in 23/100 (23\%). Complete work-up was undertaken in $18 / 100(18 \%)$ patients, as shown in table 1.

\section{Aetiology of hyponatraemia}

The aetiology of hyponatraemia was unrecorded in the notes of $58 / 100(58 \%)$ patients. Review of case notes was used to ascertain the aetiology of hyponatraemia in the remaining 42/100 $(42 \%)$ patients, as summarised in table 2. Syndrome of inappropriate antidiuretic hormone secretion (SIADH) was attributed to drugs in three cases (SSRIs in two cases and mirtazapine in one case), to malignancy in two cases (small cell lung cancer in one case and chronic lymphocytic leukaemia in one case) and to miscellaneous causes in two cases (SIADH after transsphenoidal surgery and SIADH of unknown cause).

Only 6/11 (54\%) patients diagnosed with SIADH had all the essential tests performed, including clinical assessment of volume status, measurement of paired serum and urine osmolality and $\mathrm{Na}$, and assessment of thyroid and adrenal function. ${ }^{17} 18$

\section{Effectiveness of treatment of hyponatraemia}

Correction of $\mathrm{sNa} \geq 130 \mathrm{mmol} / \mathrm{L}$ was observed in $70 / 84$ (83.3\%) patients at some point during admission, but hyponatraemia with $\mathrm{sNa}<130 \mathrm{mmol} / \mathrm{L}$ recurred in 6/84 (7.1\%). A significant proportion of patients $(53 / 84$ equal to $63.1 \%)$ had persistent hyponatraemia at discharge from hospital, as shown in table 3.

\section{Utilisation of treatment modalities}

Overall, 37/100 (37\%) patients did not have any treatment for hyponatraemia. Of the 63 patients treated for hyponatraemia, 53 received one therapeutic modality, 7 received two modalities, and 3 received three treatment modalities. First-line therapy was isotonic saline in $34 / 63(54 \%)$ cases, discontinuation of potentially offending drugs in $16 / 63$ (25.4\%), fluid restriction in $10 / 63$ (15.9\%), infusion of human albumin solution in $2 / 63(3.2 \%)$, and initiation of hydrocortisone replacement in $1 / 63(1.5 \%)$ cases. Second-line therapy was isotonic saline in 4/10 (40\%) cases, fluid restriction in 4/10 (40\%), and hypertonic saline in $2 / 10(20 \%)$. Only three patients received third-line treatment, including two cases of fluid restriction and one case of demeclocycline.

Potentially offending drugs were discontinued in $36 / 100$ (36\%) patients, with the most common being ACE inhibitors or angiotensin-II receptor antagonists (18\%), loop diuretics (15\%),

Table 1 Investigation of patients with hyponatraemia

\begin{tabular}{lllll}
\hline Investigation & $\begin{array}{l}\text { Total } \\
(\mathrm{N}=100)\end{array}$ & $\begin{array}{l}\text { Centre 1 } \\
(\mathrm{N}=38)\end{array}$ & $\begin{array}{l}\text { Centre 2 } \\
(\mathrm{N}=30)\end{array}$ & $\begin{array}{l}\text { Centre 3 }) \\
(\mathrm{N}=32)(\%)\end{array}$ \\
\hline Volume status & 62 & 71.0 & 53.4 & 59.4 \\
Serum osmolality & 39 & 39.5 & 33.3 & 43.8 \\
Urine osmolality & 33 & 39.5 & 30.0 & 28.1 \\
Urine Na & 29 & 34.2 & 36.6 & 15.6 \\
Paired osmolality-Na & 23 & 26.3 & 26.7 & 15.6 \\
Serum TSH & 61 & 71.0 & 63.3 & 46.9 \\
Serum cortisol & 31 & 34.2 & 26.6 & 31.2 \\
Full work-up & 18 & 23.7 & 20.0 & 9.4 \\
Expert input & 16 & 13.1 & 13.3 & 21.8 \\
\hline
\end{tabular}

TSH, thyroid-stimulating hormone. 
Table 2 Classification of cases according to documented aetiology of hyponatraemia

\begin{tabular}{lc}
\hline Aetiology & $\begin{array}{l}\text { Overall } \\
\text { (N=42), } \mathbf{n}(\%)\end{array}$ \\
\hline Hypovolaemic & $23(54.7)$ \\
Gastrointestinal Na losses & $9(21.4)$ \\
Poor oral intake & $7(16.6)$ \\
Diuretics & $6(14.3)$ \\
Adrenal insufficiency & $1(2.4)$ \\
Euvolaemic & $11(26.2)$ \\
SIADH due to pneumonia & $4(9.5)$ \\
Drug-induced SIADH & $3(7.1)$ \\
Malignant SIADH & $2(4.8)$ \\
Miscellaneous causes & $2(4.8)$ \\
Hypervolaemic & $8(19.1)$ \\
Decompensated cirrhosis & $4(9.5)$ \\
Heart failure & $4(9.5)$ \\
\hline SIADH, Syndrome of inappropriate antidiuretic hormone secretion. &
\end{tabular}

thiazide diuretics (10\%), potassium-sparing diuretics (10\%) and SSRIs (3\%).

In total, 76 episodes of treatment were recorded, which included isotonic saline in 38/76 (50\%) cases, drug discontinuation in $16 / 76(21.1 \%)$, fluid restriction in 16/76 (21.1\%), hypertonic saline in $2 / 76(2.6 \%)$, human albumin solution in $2 / 76$ (2.6\%), hydrocortisone replacement in 1/76 (1.3\%) and demeclocycline in 1/76 (1.3\%) cases. Use of other drug therapies for SIADH, such as tolvaptan, urea or combination of loop diuretics with oral sodium chloride, was not recorded.

\section{Effectiveness of isotonic saline and fluid restriction}

'Clear failure' of treatment with a total sNa increase of $\leq 3 \mathrm{mmol} / \mathrm{L}$ after the $72 \mathrm{~h}$ period after initiation of therapy was recorded in $4 /$ $26(15.4 \%)$ patients treated with isotonic saline compared with 8/ $10(80 \%)$ individuals managed with fluid restriction, as illustrated in table 4. Fluid restriction was imposed on 16 patients with various volumes prescribed per $24 \mathrm{~h}(1500 \mathrm{~mL}$ in 4 cases, $1000 \mathrm{~mL}$ in 9 cases, $750 \mathrm{~mL}$ in 1 case and $500 \mathrm{~mL}$ in 2 cases). Hypertonic saline was used in two patients, with infusion of $1000 \mathrm{~mL}$ saline $1.8 \%$ over $18 \mathrm{~h}$ increasing sNa by $13 \mathrm{mmol} / \mathrm{L}$, and $300 \mathrm{~mL}$ saline $1.8 \%$ over $8 \mathrm{~h}$ increasing sNa levels by $11 \mathrm{mmol} / \mathrm{L}$.

\section{DISCUSSION}

We found that hyponatraemia was frequently underinvestigated, underdiagnosed and suboptimally managed in routine practice in three hospitals in London. Urine $\mathrm{Na}$, the most important biochemical test ${ }^{19} 20$ in investigation of hyponatraemia, was measured in less than one-third of cases. The underlying aetiology

Table 3 Serum sodium ( $\mathrm{sNa}$ ) concentration at hospital discharge

\begin{tabular}{ll}
\hline SNa at discharge & $\begin{array}{l}\text { Overall } \\
\mathrm{N}=84\end{array}$ \\
\hline Patients with sNa $<125 \mathrm{mmol} / \mathrm{L}(\%)$ & 4.8 \\
Patients with sNa $125-129 \mathrm{mmol} / \mathrm{L}(\%)$ & 19.0 \\
Patients with sNa $130-134 \mathrm{mmol} / \mathrm{L}(\%)$ & 39.3 \\
Patients with sNa $\geq 135 \mathrm{mmol} / \mathrm{L}(\%)$ & 36.9 \\
Mean \pm SD sNa (mmol/L) & $132.8 \pm 4.7$ \\
\hline
\end{tabular}

Table 4 Effectiveness of isotonic saline and fluid restriction in correcting hyponatraemia in first $72 \mathrm{~h}$

\begin{tabular}{|c|c|c|}
\hline SNa correction after treatment & $\begin{array}{l}\text { Isotonic saline } \\
(\mathrm{N}=26)\end{array}$ & $\begin{array}{l}\text { Fluid restriction } \\
(\mathrm{N}=10)\end{array}$ \\
\hline Mean $\pm \mathrm{SD}$ change in $\mathrm{sNa}(\mathrm{mmol} / \mathrm{L})$ & $7.3 \pm 5.0$ & $2.8 \pm 3.2$ \\
\hline \multicolumn{3}{|l|}{ Percentage of patients } \\
\hline sNa increase $<2 \mathrm{mmol} / \mathrm{L}$ & 7.7 & 30.0 \\
\hline sNa increase $2-3 \mathrm{mmol} / \mathrm{L}$ & 7.7 & 50.0 \\
\hline sNa increase $4-8 \mathrm{mmol} / \mathrm{L}$ & 50.0 & 10.0 \\
\hline sNa increase 9-12 $\mathrm{mmol} / \mathrm{L}$ & 19.2 & 10.0 \\
\hline sNa increase $>12 \mathrm{mmol} / \mathrm{L}$ & 15.4 & 0 \\
\hline
\end{tabular}

of hyponatraemia, despite being essential to guide appropriate treatment, was unrecorded in more than half of the cases. The limited effectiveness of current management, with $63.1 \%$ of patients being discharged with persistent hyponatraemia, was not surprising considering the lack of treatment for hyponatraemia in a substantial proportion of patients. Among patients receiving treatment for hyponatraemia, isotonic saline or fluid restriction were most commonly used, with fluid restriction being ineffective in the majority of cases.

Similar results from all three hospitals indicate that insufficient diagnostic work-up and ineffective treatment of hyponatraemia may reflect UK routine care in general. There are several possible barriers to good clinical practice in this field, such as the diminished provision of undergraduate and postgraduate education in clinical chemistry in recent times, ${ }^{13} 21$ the lack of national guidelines, the absence of diagnostic algorithms and treatment pathways in most hospitals or their complexity where they exist, and the limited therapeutic options with little evidence basis for the treatment of SIADH. Besides demonstrating suboptimal standard of care for hyponatraemia, we found that fluid restriction, currently the first-line treatment for SIADH, does not correct hyponatraemia in most cases. Potential reasons are poor patient adherence because of thirst, inadequate rigour in the volume of fluid intake prescribed (which needs to be restricted to at least $500 \mathrm{~mL} /$ day less than urine output), and its questionable effectiveness per se given the limited evidence base behind its therapeutic value. ${ }^{2022}$ Therefore, clinicians should pay more attention to appropriate prescription and implementation of fluid restriction and should also have access to alternative therapeutic options such as vaptans and urea.

In comparison with previous UK studies, we recorded a higher frequency of performance of appropriate diagnostic tests. In the subgroup of our cohort with a nadir sNa $\leq 125 \mathrm{mmol} / \mathrm{L}$, $40.7 \%$ of patients had urine $\mathrm{Na}$ and $40.7 \%$ had serum cortisol measured compared with $10-18.6 \% \%^{7-10}$ and $8-15.2 \%,^{7-9} 11$ respectively, reported in other UK series using the same cut-off. It is unclear whether these findings represent a widespread rather than a local improvement in the investigation of hyponatraemia in recent years. Regarding the aetiology of hyponatraemia, SIADH was reported in only a quarter of our cases, in contrast with most studies suggesting it as the most common cause; ${ }^{18} 2324$ therefore, SIADH was probably underdiagnosed.

This study has provided insight into the contemporary investigation and management of hyponatraemia in the UK. However, it had a number of limitations. First and foremost, it could not, by its design, test whether undertreatment of hyponatraemia 
contributed to adverse patient outcomes and, more importantly, whether correcting hyponatraemia could improve clinical outcomes. Second, the small sample size and the fact that all three hospitals are in London raise the question whether the findings apply to UK clinical practice in general. Third, its retrospective nature made accurate identification of the cause of all cases of hyponatraemia impossible. As a result, its ability to evaluate the effectiveness of different therapeutic modalities was limited because failure of treatment might sometimes reflect misdiagnosis.

In conclusion, this study highlights the need to improve clinical practice. It is essential to develop tools such as electronic alert systems for severe hyponatraemia, similar to electronic alerts for acute kidney injury already introduced in several NHS hospitals. ${ }^{25-27}$ By highlighting hyponatraemia and referring to intranet-based guidelines, electronic alerts could prompt optimal investigation and treatment in a timely manner. Another innovative model of care delivery with the potential to improve standard of care is the development of multidisciplinary hospital 'hyponatraemia teams' combining the expertise of endocrinologists, nephrologists, chemical pathologists and other physicians. In addition, UK guidelines on management of hyponatraemia are still needed despite the recent publication of clinical practice guidelines by an expert panel ${ }^{22}$ and by a joint venture of the European Society of Endocrinology with the European Renal Association. ${ }^{20}$ The reason is that clinical practice and experience in the UK differ from that in the USA ${ }^{22}$ and continental Europe ${ }^{20}$ with regard to the structure of the healthcare system and the availability of treatment options, such as urea and vaptans. Finally, we agree with the authors of both European and US guidelines on the urgent need for studies evaluating the effect of correction of hyponatraemia on patient-important outcomes such as symptoms, quality of life, mortality and length of hospital stay. 2022

\section{Main messages}

- Hyponatraemia is frequently underinvestigated and underdiagnosed in UK clinical practice.

- Most patients are discharged with persistent hyponatraemia, while a substantial proportion of them have not received any treatment for hyponatraemia.

- Fluid restriction is often ineffective in correcting hyponatraemia due to SIADH.

\section{Current research questions}

- Does correction of hyponatraemia improve patient outcomes such as length of hospital stay and mortality?

- What would be the impact of measures such as introduction of electronic alert systems or widespread provision of expert input on management of inpatient hyponatraemia and patient outcomes?

- What is the optimal treatment strategy for hyponatraemia due to SIADH with regard to sodium correction and patient outcomes?

\section{Key references}

- Tzoulis P, Bagkeris E, Bouloux PM. A case-control study of hyponatraemia as an independent risk factor for inpatient mortality. Clin Endocrinol (Oxf) 2014;81:401-7.

- Huda MS, Boyd A, Skagen K, et al. Investigation and management of severe hyponatraemia in a hospital setting. Postgrad Med J 2006;82:216-19.

- Clayton JA, Le Jeune IR, Hall IP. Severe hyponatraemia in medical in-patients: aetiology, assessment and outcome. QJM 2006;99:505-11.

- Thompson C, Berl T, Tejedor A, et al. Differential diagnosis of hyponatraemia. Best Pract Res Clin Endocrinol Metab 2012;26(Suppl 1):S7-15.

- Spasovski G, Vanholder R, Allolio B, et al. Clinical practice guideline on diagnosis and treatment of hyponatraemia. Eur J Endocrinol 2014;170:G1-47.

- Verbalis JG, Goldsmith SR, Greenberg A, et al. Diagnosis, evaluation, and treatment of hyponatremia: expert panel recommendations. Am J Med 2013;126(10 Suppl 1):S1-42.

Contributors PT conceived and designed the study, monitored data collection for the whole study, cleaned and analysed the data, and drafted and revised the paper. PMB conceived and designed the study, and drafted and revised the paper. RE and AF were involved in data collection and data analysis. MB, TT, BK, MP and DN were involved in study design and patient recruitment, and drafted and revised the paper. EW, RL, NM, RE and RS were involved in patient recruitment, and drafted and revised the paper. KG designed the data collection tools, was involved in data analysis, and drafted and revised the paper. All authors approved the final version of the manuscript.

\section{Competing interests None.}

Ethics approval It was reviewed and approved by the Clinical Governance \& Clinical Audit Departments of all three institutions.

Provenance and peer review Not commissioned; externally peer reviewed.

Open Access This is an Open Access article distributed in accordance with the Creative Commons Attribution Non Commercial (CC BY-NC 4.0) license, which permits others to distribute, remix, adapt, build upon this work non-commercially, and license their derivative works on different terms, provided the original work is properly cited and the use is non-commercial. See: http://creativecommons.org/ licenses/by-nc/4.0/

\section{REFERENCES}

1 Hawkins RC. Age and gender as risk factors for hyponatremia and hypernatremia. Clin Chim Acta 2003;337:169-72.

2 Hoorn EJ, Lindemans J, Zietse R. Development of severe hyponatraemia in hospitalized patients: treatment-related risk factors and inadequate management. Nephrol Dial Transplant 2006;21:70-6.

3 Tzoulis P, Bagkeris E, Bouloux PM. A case-control study of hyponatraemia as an independent risk factor for inpatient mortality. Clin Endocrinol (Oxf) 2014:81:401-7.

4 Corona G, Giuliani C, Parenti G, et al. Moderate hyponatremia is associated with increased risk of mortality: evidence from a meta-analysis. PLOS ONE 2013;8:e80451.

5 Wald R, Jaber BL, Price LL, et al. Impact of hospital-associated hyponatremia on selected outcomes. Arch Intern Med 2010;170:294-302.

6 Zilberberg MD, Exuzides A, Spalding J, et al. Epidemiology, clinical and economic outcomes of admission hyponatremia among hospitalized patients. Curr Med Res Opin 2008:24:1601-8

7 Huda MS, Boyd A, Skagen K, et al. Investigation and management of severe hyponatraemia in a hospital setting. Postgrad Med J 2006:82:216-19.

8 Saeed BO, Beaumont D, Handley GH, et al. Severe hyponatraemia: investigation and management in a district general hospital. J Clin Pathol 2002;55:893-6.

9 Siddique $H$, Kahal $H$, Tahrani AA, et al. The management of hyponatraemia at two district general hospitals in the UK. J Eval Clin Pract 2010;16:1353-6.

10 Soran H, Alio Z, Pattison T, et al. Management of hyponatraemia: are we doing enough? QJM 2005:98:620-1. 
11 Clayton JA, Le Jeune IR, Hall IP. Severe hyponatraemia in medical in-patients: aetiology, assessment and outcome. QJM 2006;99:505-11.

12 Crook MA, Velauthar U, Moran L, et al. Review of investigation and management of severe hyponatraemia in a hospital population. Ann Clin Biochem 1999;36(Pt 2): 158-62.

13 Whyte M, Down C, Miell J, et al. Lack of laboratory assessment of severe hyponatraemia is associated with detrimental clinical outcomes in hospitalised patients. Int J Clin Pract 2009;63:1451-5.

14 Hillier TA, Abbott RD, Barrett EJ. Hyponatremia: evaluating the correction factor for hyperglycemia. Am J Med 1999;106:399-403.

15 Sterns RH, Riggs JE, Schochet SS Jr. Osmotic demyelination syndrome following correction of hyponatremia. N Eng/ J Med 1986;314:1535-42.

16 Sterns RH, Cappuccio JD, Silver SM, et al. Neurologic sequelae after treatment of severe hyponatremia: a multicenter perspective. J Am Soc Nephrol 1994:4:1522-30.

17 Bartter FC, Schwartz WB. The syndrome of inappropriate secretion of antidiuretic hormone. Am J Med 1967:42:790-806.

18 Ellison DH, Berl T. Clinical practice. The syndrome of inappropriate antidiuresis. N Engl J Med 2007;356:2064-72.

19 Thompson C, Berl T, Tejedor A, et al. Differential diagnosis of hyponatraemia. Best Pract Res Clin Endocrinol Metab 2012;26(Suppl 1):S7-15.
20 Spasovski G, Vanholder R, Allolio B, et al. Clinical practice guideline on diagnosis and treatment of hyponatraemia. Eur J Endocrinol 2014;170: G1-47.

21 Khromova V, Gray TA. Learning needs in clinical biochemistry for doctors in foundation years. Ann Clin Biochem 2008:45(Pt 1):33-8.

22 Verbalis JG, Goldsmith SR, Greenberg A, et al. Diagnosis, evaluation, and treatment of hyponatremia: expert panel recommendations. Am J Med 2013;126(10 Suppl 1): S1-42.

23 Fenske W, Stork S, Blechschmidt A, et al. Copeptin in the differential diagnosis of hyponatremia. J Clin Endocrinol Metab 2009;94:123-9.

24 Hannon MJ, Thompson CJ. The syndrome of inappropriate antidiuretic hormone: prevalence, causes and consequences. Eur J Endocrinol 2010;162(Suppl 1):S5-12.

25 Wallace K, Mallard AS, Stratton JD, et al. Use of an electronic alert to identify patients with acute kidney injury. Clin Med 2014;14:22-6.

26 Porter CJ, Juurlink I, Bisset LH, et al. A real-time electronic alert to improve detection of acute kidney injury in a large teaching hospital. Nephrol Dial Transplant 2014;29:1888-93.

27 Flynn N, Dawnay A. A simple electronic alert for acute kidney injury. Ann Clin Biochem. Published Online First: 24 Apr 2014. doi:10.1177/0004563214534832. 